Mappemonde

Revue trimestrielle sur l'image géographique et les formes du territoire

$128 \mid 2020$

Varia

\title{
Un pont chinois aux Maldives
}

Jean-Christophe Gay

\section{OpenEdition}

\section{Journals}

Édition électronique

URL : http://journals.openedition.org/mappemonde/3961

DOI : 10.4000/mappemonde.3961

ISSN : 1769-7298

Éditeur

UMR ESPACE

\section{Référence électronique}

Jean-Christophe Gay, « Un pont chinois aux Maldives », Mappemonde [En ligne], 128 | 2020, mis en ligne le 01 juillet 2020, consulté le 14 septembre 2020. URL : http://journals.openedition.org/ mappemonde/3961

Ce document a été généré automatiquement le 14 septembre 2020.

\section{c) (i) (2)}

La revue Mappemonde est mise à disposition selon les termes de la Licence Creative Commons Attribution - Pas d'Utilisation Commerciale - Partage dans les Mêmes Conditions 4.0 International. 


\title{
Un pont chinois aux Maldives
}

\author{
Jean-Christophe Gay
}

1 Le premier pont interinsulaire des Maldives a été ouvert à la circulation le 30 août 2018 (photo). Cet archipel de l'océan Indien, à $600 \mathrm{~km}$ de l'Inde et à cheval sur l'équateur, est composé de 1200 îles coralliennes s'étirant sur plus de $800 \mathrm{~km}$ du nord au sud. Le pays connaît une croissance démographique soutenue en raison d'une population très jeune ( $31 \%$ de la population a moins de 20 ans, $45 \%$ a entre 20 et 40 ans) malgré une fécondité qui a beaucoup baissé (plus de 7 enfants par femme dans les années 1980, 2,5 aujourd'hui). Sa population est passée de 100000 habitants en 1966 à plus de 400000 au dernier recensement (2014). Malé, la capitale, est la seule ville notable du pays. En un demi-siècle, sa population a crû encore plus vite, en raison d'une immigration massive provenant des autres îles du pays, avec 150000 habitants aujourd'hui, soit $38 \%$ de la population maldivienne, contre $11 \%$ et 15000 habitants en 1967. 
Le premier pont interinsulaire des Maldives

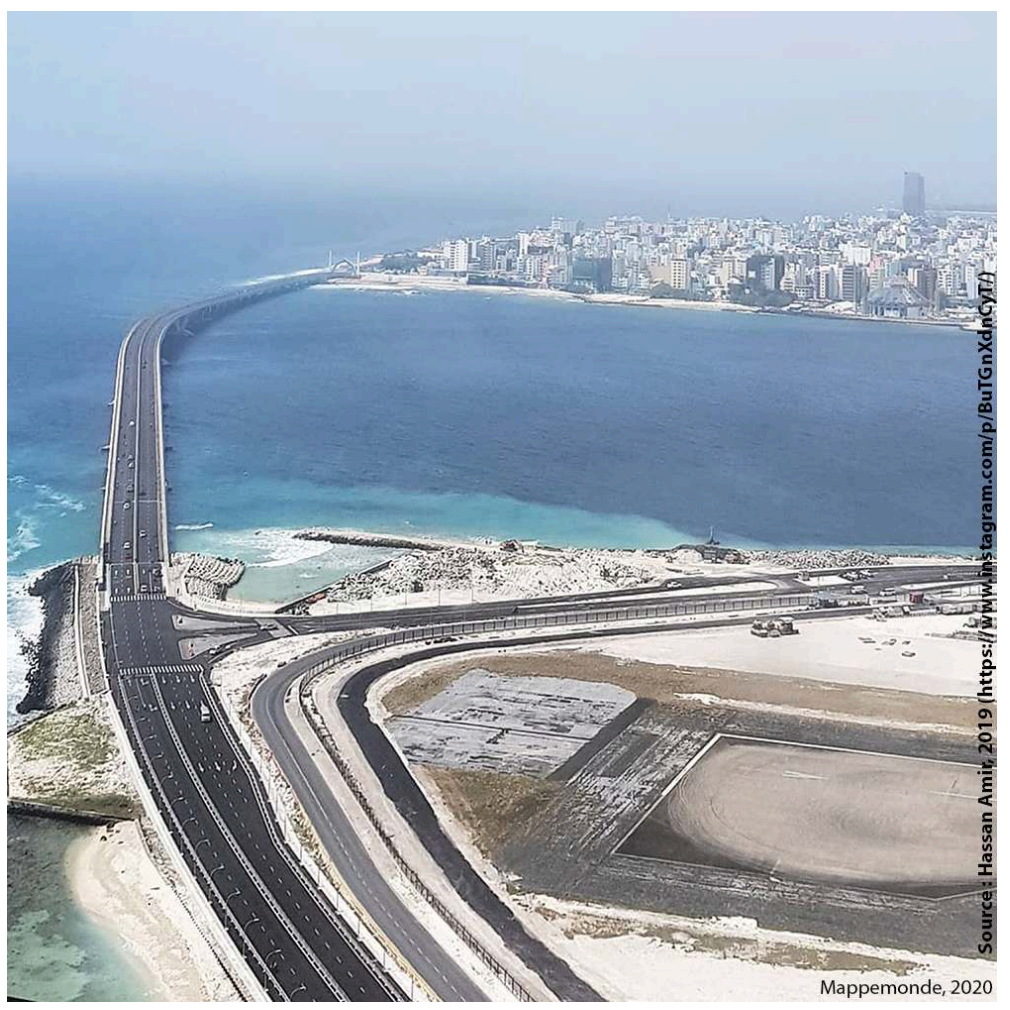

Hassan Amir, février 2019 (avec l'aimable autorisation de l'auteur de la photographie)

2 Au cœur de l'agglomération, l'île de Malé ne fait que de $2 \mathrm{~km}^{2}$, malgré les gains sur le platier récifal à partir des années 1970 (carte). La pression démographique est très élevée, avec une des densités les plus fortes du monde, puisqu'on atteint les 65000 hab./ $\mathrm{km}^{2}$. La capitale ne se réduit cependant pas à la seule île de Malé. L'urbanisation se répand sur plusieurs îles, naturelles ou artificielles. La plus célèbre est Hulhulé, l'îleaéroport, constituée de deux îles réunies en 1968 pour allonger la piste d'aviation. Celle-ci peut accueillir les long-courriers depuis 1981 avec sa piste de plus de $3000 \mathrm{~m}$ de long. Le trafic de Velana International Airport (MLE) est en constante progression, car c'est la seule porte d'entrée internationale, avec un flux touristique sans cesse croissant (114 000 touristes en 1985, 1, 484 million en 2018 et plus de 1,5 million en 2019). 


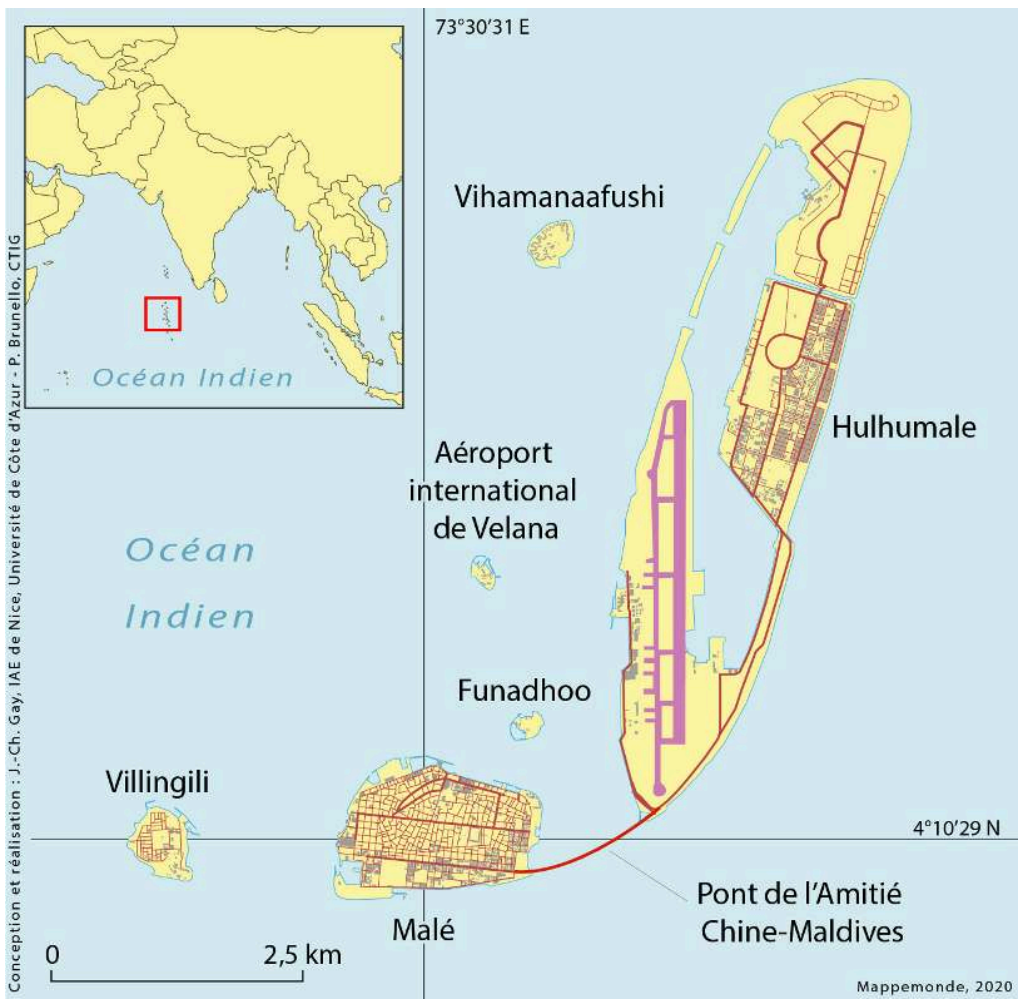

Conception : J.-Ch. Gay; Réalisation : P. Brunello, CTIG

3 Au nord-est de l'agglomération, Hulhumalé est une opération d'aménagement majeure qui a débuté en 1997. Ce nouveau terre-plein doit permettre de reloger une partie de la population de Malé et d'y installer des infrastructures portuaires, des entrepôts ou des équipements publics (mosquée, hôpital, école...). À terme, plusieurs ministères et établissements publics doivent y être relocalisés, avec l'installation de fonctionnaires. Entre Malé et l'île-aéroport, le Sinamalé Bridge, qui devrait accélérer le développement d'Hulhumalé, aurait coûté 300 millions de dollars étatsuniens. Comme son nom l'indique, la Chine en est à l'origine, avec plus de 170 millions de prêts et 100 millions de dons de Pékin. Le « pont de l'amitié Chine-Maldives » a été construit par l'entreprise China Harbour Engineering, appartenant au groupe China Communications Construction Company (CCCC). Long de 2,1 km, cet ouvrage à péage est doté de deux fois deux voies. Sur la photographie, prise en direction du sud-ouest, on reconnaît en arrière-plan la ville de Malé, dominée par la tour de 25 étages du nouvel hôpital. Au premier plan, à droite de la nouvelle voie d'accès au pont, on remarque la raquette de retournement de la piste de l'aéroport.

4 Avec l'arrivée massive des touristes chinois à partir de la fin des années 2000 (41 000 en 2008, 363000 en 2014, 283000 en 2018), représentant la première clientèle depuis 2010, ce pont symbolise la présence de plus en plus visible et pressante de la Chine, notamment au travers d'investissements dans le cadre de la stratégie des "nouvelles routes de la soie ». Comme pour d'autres pays asiatiques ou africains, l'endettement du pays vis-à-vis de la Chine est devenu préoccupant, notamment sous la présidence, de 2013 à 2018, d'Abdulla Yameen, prochinois et très influencé par le fondamentalisme wahhabite importé d'Arabie-Saoudite. Le nouveau président Ibrahim Mohamed Solih, 
démocratiquement élu en septembre 2018, a annoncé qu'il allait réorienter sa politique étrangère vers l'Inde, les États-Unis et l'Union européenne.

\section{BIBLIOGRAPHIE}

GAY J.-C. (2000). « Malé (Maldives) : une capitale multi-insulaire ». Mappemonde, $\mathrm{n}^{\circ}$ 59. En ligne :

https://www.mgm.fr/PUB/Mappemonde/M300/Clieux.pdf

GAY J.-C. (2019). « Maldives-Malé : une capitale multi-insulaire, entre gestion de fortes contraintes et aménagements ». Géoimage (CNES). En ligne : https://geoimage.cnes.fr/fr/geoimage/

maldives-male-une-capitale-multi-insulaire-entre-gestion-de-fortes-contraintes-et

\section{AUTEUR}

\section{JEAN-CHRISTOPHE GAY}

IAE de Nice, Université Côte d'Azur 